\title{
Why Should Educators Care about Argumentation?
}

\section{HARVEY SIEGEL University of Miami}

Key words: argumentation, education, educational aims, educational ideals, rationality, critical thinking, character, respect, feminism, postmodernism, indefiniteness of language, Derrida, particularity, male bias.

Abstract: Educators who are reflective about their educational endeavours ask themselves questions like: What is the aim of education? What moral, methodological, or other constraints govern our educational activities and efforts? One natural place to look for answers is in the philosophy of education, which (among other things) tries to provide systematic answers to these questions.

One general answer offered by the philosophy of education is that the aim of education consists in fostering the development of students' rationality. On this view, education has as its fundamental task both the development of students' reasoning ability, and also the fostering of a complex of attitudes, habits of mind, dispositions and character traits, such that students are not only able to reason well; they also care about reasons, and organize their beliefs, judgments and actions in accordance with the deliverances of the reasoned evaluation of reasons.

Argumentation theory is also concerned with the analysis of the power and convicting force of reasons. When do reasons for a claim warrant acceptance of that claim? By what criteria are reasons evaluated? How are these criteria themselves justified? Such questions as these are the meat and potatoes of argumentation theory, which, in pursuing these questions, promises to shed light on the character of rationality as the aim of education. Rationality, which links education and argumentation theory, provides educators with a reason to care about argumentation-if rationality can be cogently defended as an educational ideal.

In this paper I will try to provide such a defense, and in doing so explain why educators should care about argumentation. The defense will be a moral one: I will argue that we are morally obliged to endeavour to foster the rationality of students, because that is what is required to meet our obligations to treat students with respect as persons.

I will also consider some general criticisms of the Enlightenment ideal of rationality, offered by Feminist, Multiculturalist, and Postmodernist scholars. If these criticisms are cogent, then both argumentation theory and the view that the aim of education is the fostering of rationality are threatened. I will argue that the criticisms, while important and instructive, are not so destructive of the ideal of rationality as some contemporary scholars suppose.

Educators are busy people. They must worry about classroom management and discipline, about students' self-esteem, about building- and system-politics, about parents and their attitudes and involvement (or lack thereof), about misguided administrators and teachers, about funding, and about a million other things as well. Why on earth should they care about argumentation?

In what follows I will argue that they should so care, and I'll try to explain why they should.

\section{What should educators care about?}

As is typical in philosophy, so it is in this case: in order satisfactorily to answer a given question, it is necessary to turn one's attention to a prior question. In order to know whether educators should care about argumentation in particular, we 
must first figure out what they should care about in general. Then we'll know whether argumentation is included in that broader set of legitimate educational concerns. So: What should educators care about?

Obviously, they should care about many things. Educators are people, after all; they should care at least about all the things people generally ought to care about: hunger, world peace, whether the newly invented proof of Fermat's Last Theorem is successful, whether there will be a World Series this season-and if so, whether the Blue Jays will win it-and so on. But these cares, legitimate and important as they are, are pretty clearly not the sorts of things with which our question is concerned. So we need to sharpen our question a bit. We need to ask: What should educators, qua educators, care about?

The first answer here is obvious: educators, qua educators, should care about education. However intrinsically important the (Major League Baseball) umpires' strike and owners' lock-out might have been, given the looming resultant prospect that the Blue Jays would have had to play their home games this season not only not in their home stadium, but in an alien, hostile, foreign land, it is clear that these are not the concerns of educators qua educators, since they have nothing directly to do with education.

So educators qua educators ought to be concerned with education. So far, so good. But this doesn't tell us very much, since education is a many-layered, many-faceted activity. Should they be concerned with student crime? Of course. With the architectural layout of the proposed high school classroom addition? Obviously. The list could be extended indefinitely. What unites all these legitimate educational concerns is their relation to the aim of the activity: they are legitimate educational concerns because they impact upon our ability to achieve our educational ends.

Consequently, a central and abiding concern of educators qua educators involves the nature of those ends. What are we trying to accomplish by engaging in our educational activities? What ends are we trying to achieve, and how should we try to achieve them? The legitimate concerns of educators qua educators depend upon the ends, aims and ideals of education. Therefore, a fundamental concern of educators qua educators involves the nature of those aims and ideals. What are they? And why are these, and not some other things, our ultimate educational aims-that is, how are our educational aims and ideals themselves justified?

These questions are among the most basic questions addressed by the philosophy of education. So, as a next step, we can say that educators qua educators ought be concerned with philosophical questions concerning education, especially those concerning the nature and justification of basic educational aims and ideals.

So what are our fundamental educational aims and ideals? While philosophers of education have, throughout the history of the subject, addressed this question, they have not done so in a single voice. Many putative ideals have been advanced: creativity, good citizenship, various conceptions of good 
character, self-confidence, self-esteem, positive self-image, obedience to (usually select) others, obedience to the moral law, caring for and about others, reverence for and devotion to God, various kinds of knowledge, aesthetic sensitivity, and many others. Fortunately for us all, this is not the time to review and assess the strengths and weaknesses of these assorted proposed educational ideals. To do so would require that we stray far from our subject here: that is, argumentation. Instead, I want to focus on one particular educational ideal, which, I will argue, is both a fundamental educational ideal and is closely related to argumentationthat of rationality.

The idea that education should be fundamentally concerned with the fostering of rationality is one with a long and distinguished pedigree in the history of Western philosophy of education. In various terms and with various emphases and twists, it has been advocated by the vast majority of philosophers of education in the Western intellectual tradition, including Socrates, Plato, Aristotle, and others in the Ancient period; Anselm, Aquinas, Scotus, and other important Medieval philosophers; Locke, Hume, Kant, Rousseau, Mill, and others in the Modern and Enlightenment periods; and, in this century, by, among many others, Bertrand Russell, John Dewey, R. S. Peters, and Israel Scheffler.'

While I certainly don't place myself in the company of those towering philosophical figures, I have also defended the claim that the fostering of students' rationality is a fundamental educational aim, and I have tried in various places to articulate and justify the ideal. ${ }^{2}$ I shall next say a bit more about this ideal and its justification, in order to make clear its fundamental connection to argumentation.

To say that rationality is a fundamental aim or ideal of education is to say that educational activities ought to be conceived, designed, and carried out in such a way that they will conduce, ceteris paribus, to the maximal development of students' rationality. In what does this rationality consist? Briefly, in two independent features: in skills and abilities of reason assessment; and in a complex of attitudes, dispositions, habits of mind, and character traits that can collectively be labelled the critical spirit.

The first of these involves the ability of students to evaluate the epistemic force of reasons which can be offered in support of candidate beliefs, claims, and judgments - to be able to distinguish between reasons which genuinely do and genuinely do not support those candidates, and, in the cases in which they do, to determine the strength of that support. A person is rational only insofar as she can, among other things, systematically and appropriately evaluate such reasons. When we say that rationality is a fundamental educational ideal, we are claiming that education ought to strive to foster in students the skills and abilities which will enable them competently to assess reasons.

The second feature-the critical spirit-involves the character of the student. The student who has it not only is able to assess reasons well; she is disposed to do so, and to be moved to conform her beliefs, judgments and actions to the results of such assessments. She has, as Professor Binkley so admirably 
put it, a "love of reason" (Binkley 1980, p. 83), and her entire life is shaped by this view of reason and its value. When we say that rationality is a fundamental educational ideal, we are claiming that education ought to strive to foster in students the complex of attitudes, dispositions, habits of mind and character traits constitutive of the critical spirit. ${ }^{3}$

The obvious next question to ask is: why should we regard rationality, so understood, as a fundamental educational ideal? Why are we justified in regarding it as such an ideal? While there are a variety of considerations which I think argue in favor of so regarding it, the fundamental one is moral: we are morally obliged to treat students in such a way as to foster the development of their rationality, because only in treating them in that way do we honor the Kantian injunction to treat them with respect as persons. ${ }^{4}$ (This invocation of Kant's "Enlightenment" view of the importance of the individual and her autonomy has come under serious criticism of late, and we will consider it further below.)

The final preliminary, before we resume our consideration of argumentation, is to draw your attention to the normative character of the conception of rationality just sketched. Rationality, conceived as an educational ideal, is in at least two respects normative. First, obviously, it places a strong positive value on rationality; the defender of the ideal ranks it more highly than at least a lot of alternative educational ideals. But more relevant for the present discussion, it is normative in its approach to what we might call the substance of education, and indeed of thinking more generally: the defender of the ideal puts forward the claim that it is important for students to reason well, and takes as fundamental the educational task of helping students to maximize (ceteris paribus) their ability to do so. Students who reason poorly would not measure up well against the ideal. It is this aspect of the ideal's normativity that allows us to forge a link between it and argumentation. And so we are, at last, ready to consider the connection between education and argumentation afforded by the ideal of rationality.

\section{Education and Argumention}

Argumentation-whatever else it may be-is aimed at the rational resolution of questions, issues and disputes. When we engage in argumentation, we do not seek simply to resolve disagreements or outstanding questions in any old way-if we did, then instances of brainwashing, getting one's interlocutor to ingest appropriate chemicals, and issuing threats of force would count as episodes of argumentation, since these are ways of resolving questions and disputes. These ways of forging resolutions are rightly rejected as instances of argumentation precisely because the resolutions so forged are not rational ones: that is, such procedures for forging resolutions afford no confidence that the resolutions so reached are in any way rationally superior or preferable to other possible resolutions. Argumentation, that is, is concerned with/dependent upon the goodness, the normative status or epistemic forcefulness, of candidate reasons for belief, judgment, and action. ${ }^{5}$ 
When argumentation is conceived in this way, then the theory of argumentation is relatedly conceived as exploring such questions as: under what conditions are episodes of argumentation successful? That is, under what conditions are achieved resolutions of disputes rational? By what criteria is such rationality determined?

So understood, argumentation and its theory are fundamentally concerned with rationality, and with the normative evaluation of argument. As such, argumentation and argumentation theory (and informal logic) are of direct interest to educators. For as we have seen, educators - at least, those who embrace the ideal of rationality-design their educational activities in such a way that they (ceteris paribus) maximally foster the rationality of their students. Educators qua educators want their students (to be able to and) to argue well-not in the sophistic sense of being able to "win" arguments by virtue of their powers of persuasion, but in the sense of being guided by good reasons in that they base their beliefs, judgments and actions on them. Educators likewise want their students to understand why particular reasons for belief, judgment and action are more epistemically forceful than others, and to understand the criteria by which such evaluations are made, and how those criteria are themselves justified. And to these educational aims, argumentation and its theory are directly relevant. In short, since educators want their students both to argue well, and to understand the constitution of good argument, they should be interested in the theory and practice of argumentation.

Education and argumentation are united, then, by their mutual concern with rationality and the normative dimensions of reasons and reasoning. Since argumentation and its theory promise both to help achieve, and to provide insight concerning the constitution of, the educators' aim of fostering the development of rationality, the educator should care about argumentation and its theory. Here we have the answer to our initial question: educators should care about argumentation because of the close connection between the educational ideal of rationality and the normative concerns and dimensions of argumentation and argumentation theory.

It would be nice if my story could be brought to an end here. I have explained why educators should care about argumentation. The key item in my explanation is educators" commitment to the ideal of rationality, which forges the link between argumentation and education. But it would be remiss to ignore the fact that, at present, the ideal of rationality is in some circles in disrepute. So my explanation will succeed only if I can blunt recent criticisms of that ideal. It is to this task I turn next.

\section{Recent challenges to rationality as a worthy educational ideal.}

In this postmodern world, there is trouble for rationality. Earlier I briefly attempted to justify the educational ideal of rationality in terms of the Kantian moral principle of respect for persons. But it is no secret that many critics of 
"liberal", "Enlightenment" philosophy reject the individualism, and the value of rational autonomy, apparently presupposed by the Kantian principle. More fundamentally, many critics of the Enlightenment project reject the modernist valorization of rationality altogether. If they are right to do so, then the educational ideal of rationality apparently goes by the boards, and with it, my explanation of why educators should care about argumentation. So, in order to make good that explanation, I must try to defuse extant criticisms of rationality.

The critical literature here is vast, and I cannot hope to finish the job completely, or even address it adequately, in the limited space remaining. I will try to show, though, that there is reason to think that the ideal of rationality can survive at least some extant criticisms of it intact. Let me consider some of these criticisms.

\subsection{Language is too unstable to license the ideal.}

Jacques Derrida famously points to the "indefiniteness" of language and linguistic meaning and, in René Arcilla's words, "the thrall of aporia in language." In an excellent discussion of Derrida and the implications of his views of language for the philosophy of education in general and multi-cultural education in particular, Arcilla (1995) suggests that those implications are sinister for traditional philosophical aims of education:

... although philosophers continue to spin discourses in order to defer indefiniteness, this indefiniteness, like a force of nature, is bound to come back and haunt terms in the discourse. Once altered and alienated from their context, these now questionable terms stand to provoke new mouths to unweave the old discourse and another generation of pens to declare their independence from its terms. So philosophy perpetuates itself. Yet so too does indefiniteness, which remains the condition for the possibility of calling different thinkers into the conversation that keeps philosophy alive. (Arcilla (1995), pp. 168-169)

Is language as aporetic, as indefinite, as Derrida and Arcilla suggest? If so, what follows from it concerning the educational ideal of rationality? I would argue, first, that any claim to the effect that the indefiniteness of language undermines either that or any other educational ideal is itself undermined by the fact that the relevant indefiniteness, if genuine, would apply to the claim itself. I don't see why the indefiniteness and aporia which are alleged to undermine the modernist quest for educational ideals don't also impinge upon, and undermine, the very view of language that is supposedly doing the damage to the ideals-for the Derridean thesis appears to depend upon the definite establishment of the indefinite (to wit: "I, Derrida, have definitely and firmly established, in language, that all language and meaning is indefinite"). Let me amplify this point a bit.

First, consider the basic form of Arcilla's argument:

(1) Language is provisional and indefinite.

(2) Therefore, dialogue is interminable. 
(3) Therefore, philosophical ideals, which depend upon dialogue, are indefinite, inconclusive, and subject to disruption.

The first, fundamental premise is that which expresses Derrida's claim concerning the aporetic nature of language. Should we accept this premise? Not, I don't think, without qualification. Qualification is required because, unqualified, the claim it expresses is subject to a damning difficulty: if language has only provisional meaning, and is indefinite, then the premise expressing the claim is itself only provisional and indefinite. But if so, the claim is at least to some extent undermined, because its grand pronouncement about the nature of language is (to say the least) significantly limited. In other words, if language and meaning are, in general, provisional and indefinite, then so is the language expressing, and the meaning of, the Derridean claim itself. But if so, then, first, neither (2) nor (3) above follow from it; and, second, it is incapable of undermining the possibility of establishing rationality as a legitimate educational ideal. The fact that Derrida's thesis concerning aporia applies to itself undermines its ability to do the work it is here being asked to do.

Second, the self-applicability of Derrida's thesis raises another difficulty. Do we 'know' that language is aporetic? How could we, if language is in fact aporetic? This depends, of course, on what we mean by 'knowledge'. If the thesis is that one understanding of language is as good as any other, then we can't know any claim expressible in language; this of course applies to the thesis itself as well as to everything else. This is a recipe for epistemological skepticism, based on a Derridean linguistic skepticism concerning meaning. I won't pause here to consider the merits of such skepticism. But the thesis needn't be read in this stark way; it is I think more plausibly understood as recommending a form of fallibilism rather than skepticism, to wit: since language is subject to aporia, it is always possible that what we think we know (e.g., to take Arcilla's example, that he is a male) we may at some point decide that we don't know. Given the everpresent possibility of new insights, new theorizing, new evidence, and new alignments of meaning, we must always hold open the possibility that putative knowledge-claims can be revised. That knowledge is in principle revisable in this sense does not lead to skepticism, but only to fallibilism. In this sense we can know, fallibly, that language is aporetic. (Whether we do know this is of course another question.) But this is possible only if we don't hold that one understanding of language is as good as any other; but, rather, that the Derridean understanding of language as aporetic, while in principle open to revision, is the best understanding we currently have. Here knowledge, understandings, and meanings admit of evaluations in terms of better and worse. This sort of fallibilistic but non-skeptical interpretation is the one Derrideans require, if their arguments about anything are to rest upon the Derridean premise (1). But if so, then, as 1 argued above, that premise is actually much weaker than it appears. Indeed, no mention of the premise is required: we are all fallibilists now, and have been since Peirce; Derrida's discussion and thesis, understood fallibilistically, contributes nothing. Understood skeptically, it defeats itself and so also 
contributes nothing. Either way, then, the Derridean thesis is a lot less impressive than it appears at first blush. It has no apparent tendency to undermine either the quest for educational ideals in general, or the establishment of rationality as a fundamental educational ideal in particular.

\section{2 'Meta-narratives' must be rejected.}

Many postmodernist writers have argued that any 'metanarrative' concerning general educational ideals, relevant to all people, is suspect. ${ }^{7}$ Within the broader Postmodern literature, Foucault and Lyotard are famous for their rejection of metanarratives. In the literature of educational theory, Henry Giroux, for example, voices the same objection:

General abstractions that deny the specificity and particularity of everyday life, that generalize out of existence the particular and the local, that smother difference under the banner of universalizing categories are rejected [by rightminded postmodernists] as totalitarian and terroristic. (Giroux (1988), p. 14)

Other educational theorists also press the objection. If it succeeds, then it appears to undercut the explanation offered above concerning educators' interest in argumentation, since that explanation depends upon just such a metanarrative, concerning rationality. Relying on that Enlightenment metanarrative, then, would not only fail; it would also constitute, in Giroux's words, "totalitarian and terroristic" hegemonic philosophizing, and, once seen in that light, would presumably be rejected by 'liberal' philosophers as well as postmodern ones.

This objection does not succeed. For one thing, the relevant metanarrative concerning rationality does not "deny the specificity and particularity of everyday life", "generalize out of existence the particular and the local", or "smother difference under the banner of universalizing categories". It can and should acknowledge specificity and particularity, the particular and the local, and difference. It can and should, moreover, accept that difference, particularity, locality, and specificity, are highly relevant to particular educational questions. However, while the 'modernist' view accepts and acknowledges these particularities and differences-and so does not deny or smother differences, and therefore is innocent of the charges Giroux articulates-it does deem them to be irrelevant to certain questions, especially to those concerning the justifiability or correctness of the relevant principles. For example, if it is wrong to marginalize, silence, or otherwise oppress members of minority cultures, then it is wrong to do so-independently of the particularities of the cultures victimized by that oppression. Thus the Enlightenment view presumed in regarding rationality as a fundamental educational ideal acknowledges difference and particularity, but has a nuanced view of the relevance of difference: sometimes it is highly relevant; sometimes not. That view rejects the idea that difference is always relevant to everything. But that rejection escapes Giroux's criticism.

Moreover, the Postmodern rejection of metanarratives in general is notoriously troubled. As many writers have noted, that rejection itself constitutes a metanarrative. To say that all metanarratives are to be rejected, that they are all 
defective, is to make a universalizing claim of exactly the sort that the person making the claim wants to (universally) reject. But if rejecting metanarratives requires embracing a metanarrative, then there is a logical difficulty inherent in the very idea of rejecting them all. The bottom line is this: if the rejection of metanarrative requires metanarrative, then metanarrative cannot (coherently) be universally rejected. If not, then the claim that rationality is a fundamental educational ideal cannot be tellingly criticized on the grounds that it relies upon a metanarrative.

\subsection{The 'universalistic' conception of rationality is itself problematic.}

A further charge made against the view defended here is that it relies upon a hegemonic conception of 'universal reason'. It is true that that view does presuppose a particular conception of reason and rationality, according to which reasons can afford objective warrant for particular claims. This view is 'universalistic' in the sense that the goodness-the power and probative forceof reasons is universally applicable: if $p$ is a good reason for $q$, then everyone who is justified in believing that $p$, and who believes that $q$ on the basis of $p$, is likewise justified in believing that $q$. Particularities and differences among the candidate believers or their cultures do not effect the ability of $p$ to warrant $q$.

I have already argued that universality itself is not a plausible target of criticism, since it is required for its own rejection, and therefore cannot be coherently universally rejected. But many writers suggest that there are special problems here for the universality of reason or rationality in particular. Not only do different cultures and persons evaluate particular reasons differently with respect to their probative force-what you or your culture regard as a good reason for $q$, I or my culture regard as a bad reason-but a special problem arises with respect to the justification of that conception of reason or rationality itself. For how can I argue for my, or indeed any, universalistic conception of rationality? If I do so on the basis of reasons I offer in its defense, I appear to beg the question against those not already committed to that conception; if I do so on any other basis, my proffered justification fails by my own lights. Thus these two problems threaten, from another angle, any universalistic conception of rationality.

Both of the problems just raised are fundamental epistemological difficulties. I can't possibly address them here, though they have been addressed elsewhere. Siegel (1987) is aimed at defusing the first, relativistic, difficulty-i.e. that a universalistic conception of rationality is defective because the power and convicting force of reasons appears to differ from person/culture to person/culture. Siegel (1989) and (1992a) attempt to offer a non-questionbegging, non-circular rational justification of rationality itself. If the efforts undertaken in these works are successful, then these two difficulties with 'universal reason', at least, can be met. 


\subsection{We must embrace the particular, and in doing so, reject the universal.}

It has also been argued that educational ideals, like everything else, are inevitably, necessarily, particular; that the particular and the universal are mutually exclusive; and, consequently, that the attempt to identify 'universal' educational ideals such as rationality is doomed. ${ }^{8}$ That entailment is illusory, I will argue; a recognition that our proposed ideal is particular, in that it arises in a particular culturalhistorical location, in no way precludes its universality.

The idea that particularity and universality are mutually exclusive and exhaustive, i.e. the idea that we must opt for one or the other, is clearly defended in the work of Richard Rorty. Rorty contrasts "objectivity"- - the view that as philosophical inquirers we must "step outside our community long enough to examine it in the light of something which transcends it, namely, that which it has in common with every other actual and possible human community", perhaps "an ahistorical human nature" (Rorty (1989), p. 36)-with "solidarity", according to which people locate themselves with reference to some community, and which conceives inquiry and inquirers as fundamentally "ethnocentric" (37). Rorty embraces solidarity: "we must, in practice, privilege our own group, even though there can be no noncircular justification for doing so"; in doing so, he embraces "[t]his lonely provincialism, this admission that we are just the historical moment that we are". (44) He argues that striving after objectivity is but "an attempt to avoid facing up to contingency". (46)

I don't want here to offer any sort of systematic criticism of Rorty, though I believe that his general view suffers from overwhelming difficulties. ${ }^{9}$ I want instead to emphasize that, in embracing solidarity over objectivity, Rorty is rejecting the sort of universalistic, trans-historical perspective he identifies the latter tradition as striving to articulate and embrace. He holds that this sort of universality is philosophically untenable, and that the only alternative is to settle for solidarity with non-universalistic particularity. (e.g. (1989a), pp. 190-192) That is, he holds that the objectivity/solidarity dichotomy, and consequently the universality/particularity dichotomy, is exclusive and exhaustive; that, while one must embrace either particularity or universality, one cannot embrace both. Is this correct? I think not. I will next present an argument intended to establish the compatibility of the universal and the particular.

My argument is simple. The fact that humans are always located in specific cultural/historical settings does not undermine our collective ability to reach beyond our local settings and speak to broader audiences and arenas of concern. We always judge from the perspective of our own conceptual scheme; there is no way to escape from all schemes and judge from a God's-eye point of view. Since our schemes reflect our cultural/historical circumstances, then these circumstances constitute limits on our judgment; we can't escape them entirely. With these premises I agree. But some draw from them the conclusion that universality, or a perspective unencumbered by our particular situation, is 
impossible; that our judgments cannot, in principle, have any force beyond the bounds of our own location or scheme. From this conclusion I dissent.

I will not dally over the obvious logical difficulty that anyone who presses that conclusion on the basis of those (or any other) premises presumes the legitimacy of the very sort of universality she is out to reject, since she thinks that the conclusion follows-for everyone, judging from whatever conceptual/ cultural/historical scheme-from those premises. Instead, I want simply to argue that the argument is a non sequitur, and that its conclusion is false. If all of our judgments are made from the perspective of whatever scheme we happen to employ - which they are - then, according to that argument, none of them have any such legitimacy. But counter-examples to this thesis abound. Many of our arithmetical and mathematical judgments, for example, though made from our scheme, surely have legitimacy, and are correct, even though small children, and members of certain other cultures, ${ }^{10}$ do not share either our scheme or our judgments. Important scientific theories similarly have application, and validity, beyond the scheme of those who invented them and their cultural mates-space 'curves', and mass is convertible with energy, for example, even for those whose schemes do not sanction these judgments.

Counterexamples to the thesis under discussion-that the epistemic legitimacy of judgments is bounded by the perspective of the scheme from which the judgments are made-are not restricted to the mathematical and scientific domains. Moral and social/political judgments also aspire to, and sometimes achieve, extra-scheme legitimacy: for example, our judgment that oppression and marginalization are wrong, though made from the perspective of our own scheme, is thought (by us) to have legitimacy beyond the sharers of that scheme. Similarly, even though racist, patriarchal, and heterosexist schemes approve of their associated forms of marginalization and oppression, we have no difficulty in criticizing such schemes, or the judgments made within them, as inadequate or unjust. Indeed, to advocate any particular moral/social/political value is to insist upon the scheme-independent ${ }^{31}$ legitimacy of such criticism. If our stances with respect to such values do not permit this, on what basis can we advocate and try to ensure that others endorse and conform to such values as well? $?^{12}$

The central point is this: though we judge from the perspectives of our own schemes, our judgments and their legitimacy regularly extend beyond the bounds of those schemes. Thomas McCarthy, in discussing the conception of truth as ideal rational acceptability advocated by Hilary Putnam (1981), and utilizing Putnam's "immanent/transcendent" distinction, articulates the point well:

... any adequate account of truth as rational acceptability will have to capture not only its immanence-i.e., its socially situated character-but its transcendence as well. While we may have no idea of standards of rationality wholly independent of historically concrete languages and practices, it remains that reason serves as an ideal with reference to which we can criticize the standards we inherit. Though never divorced from social practices of justification, the idea of reason can never be reduced to any particular set of such practices. Correspondingly, the notion of truth, while essentially related 
to warranted assertibility by the standards or warrants of this or that culture, cannot be reduced to any particular set of standards or warrants. To put this another way, we can, and typically do, make historically situated and fallible claims to universal validity. (McCarthy 1988, p. 82)

As Putnam puts it:

If reason is both transcendent and immanent, then philosophy, as culturebound reflection and argument about eternal questions, is both in time and eternity. We don't have an Archimedean point; we always speak the language of a time and place; but the rightness and wrongness of what we say is not just for a time and a place. (Putnam (1982), p. 21, emphasis in original)

Immanence does not preclude transcendence: as both Putnam and McCarthy suggest, our judgments, while immanent, strive also for transcendence. There is no difficulty in thinking that occasionally they attain that transcendence; nor is there any reason to think that it is impossible in principle that they might. Consequently, the fact that our judgments are immanent does not entail their nontranscendence. Thus, the argument that immanence and transcendence are mutually exclusive and exhaustive, and that, since we can't escape immanence, we must reject transcendence, fails. ${ }^{13}$

Just as immanence does not entail the denial of transcendence, particularity does not entail the denial of universality. Our judgments and ideals inevitably reflect particularity: they are made by particular people, in particular historical and cultural circumstances. But this fact in no way undermines the universality of some of our ideals. Any statement, of universal principle or of anything else, will be situated and located, and will reflect the particularities of that locale; but this does not force the conclusion that such statements are not universal, either in their applicability or in their legitimacy. The particular and the universal are not mutually exclusive; at least some of our judgments are both. If so, then we are free to regard rationality-however particular the circumstances of its origin and advocacy might be--as a universal educational ideal.

\subsection{The ideal of rationality is problematically oppressive and 'male'; allegedly 'neutral' standards of rationality are not neutral.}

Many feminist philosophers, e.g. Susan Bordo, Genevieve Lloyd, Evelyn Fox Keller, Sandra Harding, and Hilary Rose, among numerous others, have argued that 'reason' is problematically 'male'. ${ }^{14}$ The central contention is clearly articulated by Louise M. Antony and Charlotte Witt:

Feminist challenges have, indeed, reached into the "'hard core' of abstract reasoning" itself, with charges that the most fundamental elements of the Western philosophical tradition-the ideals of reason and objectivity-are so deeply corrupted by patriarchy that they must be greatly transformed (if not utterly abandoned) by any philosopher committed to the development of conceptions of knowledge and reality adequate to the transformative goals of feminism. (Antony and Witt (1993), p. xiii. The embedded citation is from Harding and Hintikka (1983), p. ix.)

and by Sally Haslanger: 
... a rational stance is itself a stance of oppression or domination, and accepted ideals of reason both reflect and reinforce power relations that advantage white privileged men. (Haslanger (1993), p. 85)

and, in a critical discussion of Catharine MacKinnon, by Elizabeth Rapaport:

For MacKinnon, rationality is an enemy to be unmasked and destroyed. (Rapaport (1993), p. 129)

As MacKinnon develops the point:

The kind of analysis that such a feminism is, and, specifically, the standard by which it is accepted as valid, is largely a matter of the criteria one adopts for adequacy in a theory. If feminism is a critique of the objective standpoint as male, then we also disavow standard scientific norms as the adequacy criteria for our theory, because the objective standpoint we criticize is the posture of science. In other words, our critique of the objective standpoint as male is a critique of science as a specifically male approach to knowledge. With it, we reject male criteria for verification. (Mackinnon (1987), p. 54, last two emphases added) ${ }^{15}$

What follows from the rejection of "male criteria"? There are only two possibilities: either that there are no criteria in terms of which theories can be evaluated, or that there are different criteria which should be appealed to in theory evaluation. The first of these is deeply problematic. If there are no criteria in terms of which we can legitimately evaluate theories, then the very possibility of evaluation is rejected. But this option is self-defeating: if evaluation in general is rejected, then we are unable to evaluate, or rationally prefer, the suggestions that male criteria should be rejected or that evaluation itself should likewise be rejected. But then we have no reason to accept these suggestions. Normative evaluation cannot be entirely given up; to attempt to do so is, as Putnam suggests, to attempt "mental suicide"'s.

On the other hand, the rejection of male criteria of theory evaluation in favor of other, incompatible, 'female criteria', must itself-if the preference for the latter is to be itself defensible and non-arbitrary-rely upon (meta-)criteria in accordance with which these two rival sets of criteria can themselves be fairly evaluated. Standards and criteria are in this way required for the conducting of any sort of serious scholarly endeavor, including that of arguing for the rejection of the ideal of rationality as biased and oppressive, and likewise for the embrace of alternative feminist ideals. In short, one cannot coherently embrace the ideals of philosophical feminism, or reject as biased and oppressive the 'male' ideal of rationality, and at the same time reject standards entirely. ${ }^{17}$ And with respect to MacKinnon's rejection of the standards of science, and so science itself, as male, it is difficult not to see this as a classic instance of cutting off one's nose to spite one's face. Consider in this regard Martha Nussbaum's suggestion that feminist philosophers err if they reject reason and objectivity in their endeavor to combat patriarchy:

Convention and habit are women's enemies here, and reason their ally. Habit decrees that what seems strange is impossible and "unnatural"; reason looks head on at the strange, refusing to assume that the current status quo is either 
immutable or in any normative sense "natural". The appeal to reason and objectivity amounts to a request that the observer refuse to be intimidated by habit, and look for cogent arguments based on evidence that has been carefully sifted for bias. (Nussbaum (1994), p. 59)

Of course, to say that standards are required for the rational defense of the ideal of rationality, or that rational standards are required for any sort of serious intellectual work whatever, is not to say that particular standards, or particular understandings of them, are themselves beyond critical challenge. On the contrary, one major sort of intellectual advance is precisely the sort which allows us to realize that our standards, or our interpretations of them, have in one way or another been defective and stand in need of criticism and improvement. Indeed, one of the main contributions of feminist scholarship has been precisely to establish that particular standards, or particular applications of them, have been problematically biased against women. But it is not possible coherently to reject particular standards as biased, and simultaneously to reject standards of evaluation generally. ${ }^{18}$ For in doing the latter, one gives up the very possibility of evaluation, in which case the rejection of the rejected standard is unwarranted. Moreover, one cannot reject all standards and evaluation, and at the same time embrace particular standards. In particular, one cannot reject all standards, and the very possibility of evaluation, and at the same time embrace philosophical feminism as an ideal or as a standard of evaluation of discourses and/or theories. But if the move to reject all standards fails, then, in one form or another, standards of rationality will inevitably be embraced and endorsed by all who seriously consider the question of the justifiability of standards of rationality; and in this embrace, the ideal of rationality will be endorsed as well. Consequently, that ideal survives this particular objection unscathed.

\section{Conclusion}

I have considered, and found wanting, five challenges to the ideal of rationality; I have argued that that ideal survives the challenges put to it by (1) Derrida's view of the indefiniteness of language, (2) criticisms of metanarratives, (3) criticisms of 'universalistic' conceptions of rationality, (4) the unavoidability of the particular and the mutual exclusivity of the particular and the universal, and (5) the feminist claim that the ideal is oppressive and biased. Obviously I have dealt with these challenges quite briefly; much more needs to be said concerning them all-and concerning other challenges as well. But I hope to have said enough to suggest that the ideal is not in such trouble as its critics often suggest.

If so, then the link forged between education and argumentation, in terms of their joint interest in/commitment to the ideal of rationality and the normative evaluation of reasons, at least provisionally stands. And if so, then perhaps I will have accomplished my main aim here: to explain why educators should care about argumentation.

\footnotetext{
'For a brief discussion of this history, see Siegel (1992), pp. 108-9.
} 
${ }^{2}$ Most systematically in Siegel (1988).

${ }^{3}$ For further discussion of these two dimensions of the ideal, see Siegel (1988), chapter 2.

${ }^{4}$ For further discussion of the problem of justifying rationality as a fundamental educational ideal, see Siegel (1988), chapter 3.

${ }^{5}$ This epistemic view of argumentation is articulated in Biro and Siegel (1992) and Siegel and Biro (1995). In conceiving argumentation in this way, I differ with Binkley (1995), who assigns to logic the task of establishing standards for the correctness of reasoning, and who denies that argumentation involves any such normative, epistemic dimension.

${ }^{6}$ This discussion is taken from Siegel (1995a). I have shamelessly taken my discussion in that paper, which is concerned mainly with Arcilla's treatment of self-knowledge, and transferred my points to the present discussion of educational ideals. Although a bit unusual, I believe the transfer is successful. References to the relevant Derridean texts are provided in that paper.

${ }^{7}$ The discussion in this and the following sub-section is taken from Siegel (1995). Again, relevant changes have been made.

"The discussion in this sub-section and the next is taken from Siegel (1995b); again, relevant changes have been made.

${ }^{9}$ In particular, it is unclear why we should accept Rorty's claim that the impossibility of objectivity or universality follows from or is entailed by contingency-especially in light of the fact that the very notion of entailment on which this argument depends is itself only understandable in universalistic terms, i.e. such that the premises entail the conclusion, whoever is considering the argument. (Of course Rorty wants sometimes to reject the very idea that he is arguing (Rorty (1989a), p. 44), despite the fact that his writing is full of arguments, and would be unintelligible without the assumption that he is in fact engaging in argumentation.) The argument-language, self and community are contingent; therefore, universality is impossible or unachievable-is simply a non sequitur.

${ }^{10}$ For example, the ancient Greeks before the invention/discovery of irrational numbers; nineteenth century mathematicians before Cantor's discoveries concerning the sizes of infinite sets; nineteenth century geometers before the discovery of non-Euclidean geometries; bettors and businesspeople of the middle ages before the development of the modern probability calculus; etc.

"I here use "scheme-independent" not in the sense of being not embedded in any scheme, but rather in the sense of having legitimacy and point beyond the bounds of the scheme in which it is embedded.

${ }^{12}$ It is worth pointing out that universalistic "Enlightenment" ideals, e.g of the dignity of human reason and the commitment to decide matters on the basis of reasons, themselves can and should be understood in this way. These ideals arose and gained currency in particular historical/cultural circumstances (in ancient Greece, and in the "Age of Enlightenment" in Europe), but that fact in no way undercuts whatever universal validity they enjoy.

${ }^{13}$ I hasten to note that I do not myself advocate the idea that truth should be understood in terms of ideal rational acceptability; I favor a conception, advocated by an earlier Putnam, of truth as "radically non-epistemic" and as unconnected to considerations of rational acceptability. For further discussion see Siegel (1989a), pp. 132-3 and passim.

${ }^{14}$ Among many other sources, see the essays in Alcoff and Potter (1993) and in Antony and Witt (1993). Several essays in the latter dispute this contention, though.

is It should be noted that, on MacKinnon's view, 'rationality' is synomymous, with "objectivity"; she does not distinguish between the two, but rather rejects it/them both. (Rapaport (1993), p. 129) MacKinnon understands objectivity as "the nonsituated, distanced standpoint" (1987, p. 50); as I hope is clear, this is not the understanding of it I am utilizing 
here, since situatedness does not preclude (on my understanding of it) objectivity. For what I hope is a more nuanced and defensible understanding of the concepts of rationality and objectivity, and their interrelationship, see Neiman and Siegel (1993).

${ }^{16}$ Putnam (1982), p. 20. For more general discussion of the self-defeating character of the rejection of normative evaluation, see Siegel (1987) and (1996).

${ }^{17}$ For discussion of the general case, see Siegel (1987). Antony (1993, esp. pp. 190, 208-210) argues determinedly that radical feminists need to recognize and utilize a traditional conception of truth and traditional ideals of objectivity and impartiality, and to recognize (more or less) traditional standards of philosophical and empirical argumentative quality, if they are to achieve the aims either of feminism in particular or of political radicalism in general.

${ }^{18}$ Nor is it wise, as Nussbaum points out (1994, pp. 60-1), to reject a standard on grounds of its misuse. Concerning those who "have used the claim of objectivity to protect their biased judgments from rational scrutiny", Nussbaum writes: "More than a little perversely, some feminists have blamed this behavior on the norm of objectivity itself, rather than on its abusers."

\section{References}

Alcoff, Linda, and Elizabeth Potter, eds., (1993): Feminist Epistemologies, New York: Routledge.

Antony, Louise M. (1993): "Quine as Feminist: The Radical Import of Naturalized Epistemology", in Antony and Witt (1993), pp. 185-225.

Antony, Louise M., and Charlotte E. Witt (1993): A Mind of One s Own: Feminist Essays on Reason and Objectivity, Boulder: Westview Press.

Arcilla, René Vincente (1995): "For the Stranger in My Home: Self-Knowledge, Cultural Recognition, and Philosophy of Education", in Wendy Kohli, ed., Critical Conversations in Philosophy of Education, New York: Routledge, pp. 159-172.

Binkley, Robert W. (1980): "Can the Ability to Reason Well Be Taught?", in J. A. Blair and R. H. Johnson, eds., Informal Logic: The First International Symposium, Inverness, California: Edgepress, pp. 79-92.

Binkley, Robert W. (1995): "Argumentation, Education and Reasoning", this volume, pp. 127-143.

Biro, John, and Harvey Siegel (1992): "Normativity, Argumentation, and an Epistemic Theory of Fallacies", in F. van Eemeren, et al., eds., Argumentation llluminated: Selected Papers from the 1990 International Conference on Argumentation, Amsterdam: SICSAT, 1992, pp. 85-103.

Giroux, Henry (1988): "Postmodernism and the Discourse of Educational Criticism", Journal of Education, vol. 170, no. 3, pp. 5-30.

Harding, Sandra, and Merrill B. Hintikka, eds., (1983): Discovering Reality: Feminist Perspectives on Epistemology, Metaphysics, Methodology, and Philosophy of Science, Dordrecht: D. Reidel.

Haslanger, Sally (1993): "On Being Objective and Being Objectified", in Antony and Witt (1993), pp. 85-125.

MacKinnon, Catharine (1987): Feminism Unmodified: Discourses on Life and Law, Cambridge: Harvard University Press. 
McCarthy, Thomas (1988): "Scientific Rationality and the 'Strong Program" in the Sociology of Knowledge", in E. McMullin, ed., Construction and Constraint: The Shaping of Scientific Rationality, Notre Dame, Indiana: University of Notre Dame Press, pp. 75-95.

Neiman, Alven, and Harvey Siegel (1993): "Objectivity and Rationality in Epistemology and Education: Scheffler's Middle Road", Synthese, vol. 94, no. 1, pp. 55-83.

Nussbaum, Martha (1994): "Feminists and Philosophy", The New York Review of Books, vol. 41 , no. 17 , October 20 , pp. 59-63.

Putnam, Hilary (1981): Reason, Truth and History, Cambridge: Cambridge University Press.

Putnam, Hilary (1982): "Why Reason Can't Be Naturalized", Synthese, vol. 52, no. 1, pp. 3-23.

Rapaport, Elizabeth (1993): "Generalizing Gender: Reason and Essence in the Legal Thought of Catharine MacKinnon", in Antony and Witt (1993), pp. 127-143.

Rorty, Richard (1989): "Solidarity or Objectivity?", in Michael Krausz, ed., Relativism: Interpretation and Confrontation, Notre Dame: University of Notre Dame Press, pp. 35-50.

Rorty, Richard (1989a): Contingency, Irony, and Solidarity, Cambridge: Cambridge University Press.

Siegel, Harvey (1987): Relativism Refuted: A Critique of Contemporary Epistemological Relativism, Dordrecht: D. Reidel.

Siegel, Harvey (1988): Educating Reason: Rationality, Critical Thinking, and Education, New York and London: Routledge.

Siegel, Harvey (1989): "Why Be Rational? On Thinking Critically about Critical Thinking", Institute for Critical Thinking Resource Publication, Series 2, no. 1, Montclair State College, pp. 1-15.

Siegel, Harvey (1989a): "Epistemology, Critical Thinking, and Critical Thinking Pedagogy", Argumentation, vol. 3, no. 2, pp. 127-140.

Siegel, Harvey (1992): "Education and the Fostering of Rationality", in R. Talaska, ed., Critical Reasoning in Contemporary Culture: Theoretical Perspectives on the Meaning, Conditions, and Goals of Critical Reasoning, SUNY Press, 1992, pp. 89112.

Siegel, Harvey (1992a): "Rescher on the Justification of Rationality", Informal Logic, vol. 14, no. 1, pp. 23-31,

Siegel, Harvey (1993): "Gimme That Old-Time Enlightenment Meta-Narrative: Radical Pedagogies (and Politics) Require Old-Fashioned Epistemology (and Moral Theory)", Inquiry: Critical Thinking Across the Disciplines, vol. 11, no. 4, pp. 1, 17-22.

Siegel, Harvey (1995): “Radical' Pedagogy Requires 'Conservative' Epistemology", Journal of Philosophy of Education, vol. 29, no. 1, pp. 33-46.

Siegel, Harvey (1995a): "Knowledge and Certainty; Feminism, Postmodernism, and Multi-Culturalism", in Wendy Kohli, ed., Critical Conversations in Philosophy of Education, New York: Routledge, pp. 190-200.

Siegel, Harvey (1995b): "What Price Inclusion?", in Alven Neiman, ed., Philosophy of Education 1995, Urbana, Illinois: Philosophy of Education Society, pp. 1-22.

Siegel, Harvey (1996): "Naturalism and the Abandonment of Normativity", in W. O'Donohue and R. Kitchener, eds., Psychology and Philosophy: Interdisciplinary Problems and Responses, London: Sage, in press. 


\section{Harvey Siegel}

Siegel, Harvey, and John Biro (1995): "Epistemic Normativity, Argumentation, and Fallacies", in F. van Eemeren, et. al., eds., Analysis and Evaluation: Proceedings of the Third ISSA Conference on Argumentation, Amsterdam, June 1994, Amsterdam: SICSAT, pp. 286-299.

HARVEY SIEGEL

DEPARTMENT OF PHILOSOPHY

UNIVERSITY OF MIAMI

P.O. BOX 248054

CORAL GABLES, FL 33124-4670 